\title{
Plant-Derived Flavanol (-)Epicatechin Enhances Angiogenesis and Retention of Spatial Memory in Mice
}

\author{
Henriette van Praag, ${ }^{1}$ Melanie J. Lucero, ${ }^{1}$ Gene W. Yeo, ${ }^{3}$ Kimberly Stecker, ${ }^{1}$ Neema Heivand, ${ }^{1}$ Chunmei Zhao, ${ }^{1}$ Ed Yip, ${ }^{1}$ \\ Mia Afanador, ${ }^{1}$ Hagen Schroeter, ${ }^{2}$ John Hammerstone, ${ }^{2}$ and Fred H. Gage ${ }^{1}$ \\ ${ }^{1}$ Laboratory of Genetics, The Salk Institute for Biological Studies, La Jolla, California 92037, ${ }^{2}$ Mars Incorporated, Rockville, Maryland 20850, and \\ ${ }^{3}$ Crick-Jacobs Center for Theoretical and Computational Biology, The Salk Institute for Biological Studies, La Jolla, California 92037
}

Diet and exercise have a profound impact on brain function. In particular, natural nutrients found in plants may influence neuronal survival and plasticity. Here, we tested whether consumption of a plant-derived flavanol, ( - epicatechin, enhances cognition in sedentary or wheel-running female C57BL/6 mice. Retention of spatial memory in the water maze was enhanced by ingestion of $(-)$ epicatechin, especially in combination with exercise. Improved spatial memory was associated with increased angiogenesis and neuronal spine density, but not newborn cell survival, in the dentate gyrus of the hippocampus. Moreover, microarray analysis showed upregulation of genes associated with learning and downregulation of markers of neurodegeneration in the hippocampus. Together, our data show that ingestion of a single flavanol improves spatial memory retention in adult mammals.

Key words: flavanols; (-)epicatechin; learning and memory; Morris water maze; angiogenesis; spines

\section{Introduction}

Diet and exercise play an essential role in health and longevity. Physical activity and a diet containing fruits and vegetables reduce the incidence of cancer, diabetes, and heart disease (Powell and Blair, 1994; Steinmetz and Potter, 1996). It is less well known that these benefits extend from the periphery to brain function. In humans and rodents, physical activity enhances cognition (van Praag et al., 1999; Winter et al., 2007), counteracts age-related memory decline (Kramer et al., 1999; van Praag et al., 2005), and attenuates neurological markers of neurodegenerative diseases (Friedland et al., 2001; Tillerson et al., 2003; Adlard et al., 2005). Similarly, caloric restriction enhances neurotrophin expression and neurogenesis (Lee et al., 2002), moderates Alzheimer's disease symptoms (Mattson, 2000; Patel et al., 2005), and protects the brain from oxidative stress (Hyun et al., 2006). Both exercise and phytochemical-containing dietary supplements can improve aging-related and injury-associated cognitive deficits (Griesbach et al., 2004; Milgram et al., 2005).

\footnotetext{
Received Feb. 28, 2007; revised April 24, 2007; accepted April 24, 2007.

This work was supported by Defense Advanced Research Projects Agency Grant DAAD19-02-1-0267. The content of the information does not necessarily reflect the position or the policy of the Government, and no official endorsement should be inferred. We thank Karen Suter, Caroline Gordon, Caitlin Utschig, Morgan Allen, and Alice Smith for animal care; Eunice Meija, Heather Jepsen, and Alexis Huynh for help with histology; Brad Aimone and Lindsey Aimone for assistance with microarray preparation and analysis; Stefan Aigner and Sigal Savaldi-Goldstein for Q-PCR advice; Elizabeth Grabowski and Jamie Simon for help with figure preparation; Gabriel Barrera for technical assistance; Mark Kelm and Barry Jacobs for help with initial experiments; Tiffany Shubert and Michael Saxe for data analysis; T. Momma and J. Ottaviani for HPLC analysis; Charles Ribak for comments on this manuscript; Mary Lynn Gage for editing this manuscript; and Mars Incorporated for (-)epicatechin.

Correspondence should be addressed to Dr. Fred H. Gage, Laboratory of Genetics, The Salk Institute for Biological Studies, 10010 North Torrey Pines Road, La Jolla, CA 92037. E-mail: gage@salk.edu.

H. van Praag's present address: Laboratory of Neurosciences, National Institute on Aging Intramural Research Program, Baltimore, MD 21224.

D0I:10.1523/JNEUROSCI.0914-07.2007

Copyright $\odot 2007$ Society for Neuroscience $\quad$ 0270-6474/07/275869-10\$15.00/0
}

Foods and beverages such as grapes, blueberries, tea, and cocoa are the principal sources of flavanols (Scalbert and Williamson, 2000), a subclass of phytochemicals known as flavonoids (Butterfield et al., 2002). In cell culture, flavanols have neuroprotective (Reznichenko et al., 2005), anti-oxidant, and antiapoptotic properties (Schroeter et al., 2001; Koh et al., 2004). In vivo, flavanol-rich green tea (Haque et al., 2006), blueberries (Joseph et al., 1999), pomegranates (Hartman et al., 2006), and strawberries enhance memory and synaptic plasticity (Maher et al., 2006). However, the active components of these flavonoidrich foods remain undefined. The monomeric flavanol (-)epicatechin is of particular interest because this compound and its metabolites have been identified as bioactive molecules in vivo (Schroeter et al., 2006). Specifically, (-)epicatechin is absorbed into circulation after ingestion of flavanol-containing foods (Schroeter et al., 2006) and may cross the blood-brain barrier (Abd El Mohsen et al., 2002).

Recent studies in humans show that $(-)$ epicatechin-rich foods and purified ( - )epicatechin improve cardiovascular function (Heiss et al., 2005; Schroeter et al., 2006). In addition, imaging studies in humans drinking a flavanol-rich cocoa beverage showed enhanced cortical blood flow (Fisher et al., 2006; Francis et al., 2006). Increased cerebrovascular function, especially in the hippocampus, a brain region important for memory, may facilitate adult neurogenesis (Gage, 2000; Pereira et al., 2007). Indeed, newborn hippocampal cells cluster near blood vessels (Palmer et al., 2000), proliferate in response to vascular growth factors (Jin et al., 2002), and may influence learning (Aimone et al., 2006). However, the basic mechanisms of action of $(-)$ epicatechin remain unknown. Therefore, in addition to investigating angiogenic and neurogenic effects of flavanol consumption, microarray analysis of hippocampal tissue from mice treated with $(-)$ epicatechin was performed. 
Here, we show that (-)epicatechin improves spatial memory in mice and that this effect is enhanced in combination with exercise. In addition, angiogenesis but not new cell survival is increased in the dentate gyrus (DG) of the hippocampus of $(-)$ epicatechin-treated mice. Furthermore, microarray analysis showed that genes associated with learning and angiogenesis increase in expression, whereas inflammation and cell death genes are reduced. Together, our data indicate that flavanol consumption improves memory function.

\section{Materials and Methods \\ Subjects}

Female C57BL/6 mice (The Jackson Laboratory, Bar Harbor, ME), 8-10 weeks old, were housed individually in standard cages with a reversed day/night cycle: lights on at 10:00 P.M. and off at 10:00 A.M. Mice $(n=$ $10-12$ per group) were fed either control or ( - )epicatechin diet ad libitum. In some experiments, mice were divided into sedentary and running groups (11-12 mice per group). Runners were placed in a cage with a running wheel (Lafayette Instruments, Indianapolis, IN) for $2 \mathrm{~h}$ per day (10:00 A.M. to 12:00 P.M.) and then returned to standard housing. During the first $10 \mathrm{~d}$ of the food studies, mice received a daily intraperitoneal injection of bromodeoxyuridine (BrdU; dissolved in $0.9 \%$ saline, filtered sterile at $0.2 \mu \mathrm{m}, 50 \mathrm{mg} / \mathrm{kg}$ body weight at $10 \mu \mathrm{g} / \mathrm{ml}$; Sigma, St. Louis, $\mathrm{MO})$ to label dividing cells. At the end of the experiments, animals were given an overdose of anesthetics and perfused transcardially with cold $4 \%$ paraformaldehyde (PFA) in $0.1 \mathrm{~m}$ PBS. After $24 \mathrm{~h}$, tissue was equilibrated in $30 \%$ sucrose. Sequential coronal sections ( $40 \mu \mathrm{m})$ were taken through the hippocampus and stored in phosphate-buffered glycerol at $-20^{\circ} \mathrm{C}$.

\section{Spatial learning}

Mice were trained in the Morris water maze for $8 \mathrm{~d}$ (Morris et al., 1982). Mice were trained with two trials per day in the experiments that included running and with four trials daily in studies in which the mice were sedentary. The platform was hidden $1 \mathrm{~cm}$ below the surface of water made opaque with white nontoxic paint. The platform was located in the northwest quadrant of the water maze. The starting points were changed every trial. Each trial lasted either until the mouse had found the platform or for a maximum of $40 \mathrm{~s}$. All mice were allowed to rest on the platform for $10 \mathrm{~s}$ at the end of each trial. To test retention of the task, the platform was removed, and mice were given probe trials. The latency to the platform, length of swim path, and swim speed were recorded semiautomatically by a video tracking system (Ethovision; Noldus, Wageningen, The Netherlands).

\section{Compound administration}

Mice ( $n=10-12$ per group) were fed control diet pellets or a treatment diet, which consisted of the control diet supplemented with (-)epicatechin at a level of $500 \mu \mathrm{g} / \mathrm{g}$ (Research Diets, New Brunswick, NJ). The food was available ad libitum and based on an average food consumption of $5 \mathrm{~g}$ per animal per day; the average daily dose was $2.5 \mathrm{mg}$ of (-)epicatechin. In an experiment to determine whether $(-)$ epicatechin crosses the blood-brain barrier, mice ( $n=5$ per group) were given a purified, protein-based diet of similar macronutrient and micronutrient profiles as the control diet detailed above, which was supplemented with various amounts of $(-)$ epicatechin to achieve an average daily dose of 0,3 , or 30 mg per animal.

An additional study ( $n=7-8$ mice per group) was done to define the dose-response of (-)epicatechin and to compare it to the glutamatergic antagonist memantine at a dose shown to enhance memory in mice (Minkeviciene et al., 2004). In this experiment, the compounds were dissolved in the drinking water. After pilot studies showing that mice drink $\sim 4 \mathrm{ml}$ per day, all compounds were dissolved in water to achieve a daily dose of $0,3,15$, and $30 \mathrm{mg}$ of (-)epicatechin or $0.6 \mathrm{mg}$ of memantine $(30 \mathrm{mg} / \mathrm{kg} / \mathrm{d})$.

\section{Experimental procedure}

$(-)$ Epicatechin consumption and exercise. Mice were randomly assigned to sedentary or running groups and fed a control or ( - )epicatechin diet for 6 weeks. The running groups were in cages with running wheels from 10:00 A.M. to 12:00 P.M. Behavioral testing in the Morris water maze was performed between 8:00 A.M. and 10:00 A.M., starting on day 31 with two trials per day for $8 \mathrm{~d}$. Probe trials were done on day $8,4 \mathrm{~h}$ after the last trial, and $24 \mathrm{~h}$ later.

$(-)$ Epicatechin in food in sedentary mice. Animals were assigned to control or compound diet for 2 weeks. After 2 weeks of test or control compound, all mice received control diet. Training in the Morris water maze for $8 \mathrm{~d}$ with four trials daily began 1 week later. Probe trials were performed on days 4,6 , and 8 of training and $24 \mathrm{~h}, 1$ week, and 2 weeks after the last acquisition trial.

$(-)$ Epicatechin in water in sedentary mice. Mice drank (-)epicatechin, memantine solution, or water for $21 \mathrm{~d}$ in $15 \mathrm{ml}$ sipper tubes so that liquid intake could be measured. On day 22, all mice were switched to regular drinking water bottles. Testing in the Morris water maze started on day 23 with four trials daily for $8 \mathrm{~d}$. Probe trials were done on days 5 and 8 of training and $24 \mathrm{~h}$ and 1 week later after the last training trial.

\section{Immunohistochemistry}

Immunohistochemistry for BrdU was performed on a one-in-six series of free-floating $40 \mu \mathrm{m}$ coronal sections that were pretreated for BrdU immunohistochemistry by denaturing DNA, as described previously (van Praag et al., 1999). The antibody used was rat anti-BrdU (Accurate, 1:250; Harlan Sera-Lab, Loughborough, UK). To visualize the BrdUlabeled cells, staining for BrdU with the peroxidase method was used (ABC system, with biotinylated donkey anti-rat antibodies and diaminobenzidine as chromogen; Vector Laboratories, Burlingame, CA). Cells were counted at $40 \times$ using an upright bright-field microscope (Leitz, Wetzlar, Germany).

\section{Vasculature}

Lectin staining (Lycopersicon esculentum; Vector Laboratories) was used to visualize hippocampal blood vessels (van Praag et al., 2005). A one-in-six series of sections was rinsed with Tris-buffered saline (TBS) and blocked for $30 \mathrm{~min}$ at room temperature in a solution of TBS containing $5 \%$ preimmune donkey serum and $0.3 \%$ Triton $\mathrm{X}-100\left(\mathrm{TBS}^{2+}\right)$. Sections were incubated at $4^{\circ} \mathrm{C}$ for $72 \mathrm{~h}$ with biotinylated lectin diluted at 1:4000 in $\mathrm{TBS}^{2+}$. Thereafter, sections were rinsed with TBS and incubated for $3 \mathrm{~h}$ in streptavidin Cy3 (1:500), followed by 4'-6-diaminodino-2-phenylindole for $10 \mathrm{~min}$.

For quantification of the area covered by blood vessels, the right side of the hippocampus was imaged at $10 \times$ using the Bio-Rad (Hercules, CA) R2100 confocal system. Specifically, $123-\mu$ m-thick optical sections through the hippocampus were taken for five equidistant sections (240 $\mu \mathrm{m}$ between sections) from each brain. Subsequently, the z-stacks were merged using MetaMorph version 6.1 (Molecular Devices, Downingtown, PA). Using this program, the outline of the DG, including the hilus and molecular layer, and areas CA 3 and CA1 was traced. In each subregion (DG, area CA3, and area CA1), the amount of vessel staining was determined semiautomatically with MetaMorph. To define lectinpositive vessels, threshold was set based on luma and brightness, and the region of interest was traced by the experimenter who was blind to the treatment groups. Subsequently, the percentage of area positive for lectin-stained vessels was calculated by the software.

\section{Spine-density measurements}

Sedentary and running mice ( $n=4$ per group) were fed $(-)$ epicatechin or control diet for 6 weeks and perfused as described above. Brains were stored in $4 \% \mathrm{PFA}$ at $4^{\circ} \mathrm{C}$. Coronal sections $(100 \mu \mathrm{m})$ were cut with a vibratome. For DiI labeling, brain sections were washed with PBS, and DiI crystals were placed in the middle of the granule cell layer. DiI-labeled brain sections had coverslips applied with ProLong Antifade mounting medium (Invitrogen, Eugene, OR) and were coded so that the experimenter was blind to the treatment groups. Sections were examined under the microscope $16-24 \mathrm{~h}$ after dye placement. Images of labeled dendritic processes in the outer half of the molecular layer were taken with a Bio-Rad R2100 confocal system with a $40 \times$ oil lens and a zoom of 6 (numerical aperture, 1.4; Olympus, Tokyo, Japan). Total protrusion and mushroom spine densities were analyzed as described previously (Zhao et al., 2006). 
Analysis of Affymetrix genome array and real-time quantitative PCR Sedentary or running mice that received 6 weeks of control or $(-)$ epicatechin diet were deeply anesthetized by intraperiotoneal injection of a mixture of ketamine ( $75 \mathrm{mg} / \mathrm{kg})$, xylazine $(4 \mathrm{mg} / \mathrm{kg})$, and acepromazine $(5.6 \mathrm{mg} / \mathrm{kg})$ and decapitated. The hippocampus was dissected and frozen immediately on dry ice. Tissue from the four treatment groups [control sedentary (CS), control running (CR), (-)epicatechin sedentary (ES), and $(-)$ epicatechin runner (ER)] was processed $(n=5$ mice per group total, and a subset of $n=3$ per group was used for the array). Specifically, total RNA was isolated from the hippocampal tissue using Trizol (Invitrogen, Gaithersburg, MD). The synthesis of cDNA targets and hybridization to Affymetrix (Santa Clara, CA) MOE430_2 mouse genome arrays were performed according to the manufacturer's instructions. Affymetrix CEL files obtained from scanning of the GeneChip arrays were normalized using the apt-probeset-summarize function (pliermm-sketch) in the Affymetrix Power Tools. The gene-level normalized expression data were divided into four sets, namely CS, CR, ES, and ER. We computed $t$ statistics for each probe set comparing ER versus CR and ES versus CS. For example, we defined the $t$ statistic comparing ER versus $\mathrm{CR}$ as $t_{\mathrm{ER}, \mathrm{CR}}=\left(\mu_{\mathrm{ER}}-\mu_{\mathrm{CR}}\right) / \mathrm{sqrt}\left(\left(\left(n_{\mathrm{ER}}-1\right) \sigma_{\mathrm{ER}}^{2}+\left(n_{\mathrm{CR}}-\right.\right.\right.$ 1) $\left.\left.\left.\sigma_{\mathrm{CR}}^{2}\right)\left(n_{\mathrm{ER}}+n_{\mathrm{CR}}\right)\right) /\left(\left(n_{\mathrm{ER}} n_{\mathrm{CR}}\right)\left(n_{\mathrm{ER}}+n_{\mathrm{CR}}-2\right)\right)\right)$, where $n_{\mathrm{ER}}$ and $n_{\mathrm{CR}}$ are the number of replicates, $\mu_{\mathrm{ER}}$ and $\mu_{\mathrm{CR}}$ are the means, and $\sigma^{2}{ }_{\mathrm{ER}}$ and $\sigma_{\mathrm{CR}}^{2}$ are the variances of the expression values for the two datasets. Next, the $t$ statistics $t_{\mathrm{ER}, \mathrm{CR}}\left(x\right.$-axis) and $t_{\mathrm{ES}, \mathrm{CS}}(y$-axis) for all probe sets were displayed as a two-dimensional scatter plot, and a $t$ statistic cutoff of 4.6 corresponded to a $p$ value cutoff of 0.005 (see Fig. 6). Probe set mappings to Refseq genes were obtained via Ensembl (www.ensembl.org). Gene descriptions for Refseq genes were obtained via the University of California, Santa Cruz genome browser (genome.ucsc.edu). Gene ontology analysis was performed as described previously (Yeo et al., 2005).

Expression changes of genes of interest were verified by quantitative reverse transcription-PCR (Q-PCR). cDNA was synthesized (Superscript III; Invitrogen, San Diego, CA) from $1 \mu \mathrm{g}$ of RNA from the samples used for Genechip analysis ( $n=3$ per group) as well as from RNA from the two additional mice in each group ( $n=5$ total per group). Primer3 (Rozen and Skaletsky, 2000) was used to design oligonucleotide primers (Allele Biotechnology and Pharmaceuticals, San Diego, CA). Q-PCR was performed using SYBR Green Master Mix (Applied Biosystems, Foster City, CA) and $0.2 \mu \mathrm{M}$ of each primer in a $25 \mu \mathrm{l}$ reaction in triplicate in an Applied Biosystems Prism 7700 Sequence Detection System. Data analysis was performed using Sequence Detection Systems version 2.1 (Applied Biosystems). A mixture of the cDNAs from each sample was used to generate the standard curve. Expression of each gene of interest was calculated based on the standard curve for a given primer set. The relative amount of the calculated message was normalized to the level of a control gene: ribosomal protein L13a (Rpl13A), for which primers were obtained from RealTimePrimers (Philadelphia, PA).

\section{Flavanol analysis of brain samples}

Mice ( $n=5$ per group) that had consumed 0,3 , or $30 \mathrm{mg}$ of $(-$ )epicatechin per day for $13 \mathrm{~d}$ were perfused with Dulbecco's PBS (magnesium and calcium free, $\mathrm{pH} 7.4)$ containing EDTA (1 mM), apotransferrin (1 $\mathrm{mg} / \mathrm{ml})$, $\mathrm{L}$ - ascorbic acid $(2 \mathrm{mM})$, and reduced glutathione $(100 \mu \mathrm{M})$. Each brain was rinsed in Dulbecco's PBS (magnesium and calcium free, $\mathrm{pH}$ 7.4) containing EDTA ( $5 \mathrm{~mm})$, EGTA ( $2 \mathrm{~mm})$, L-ascorbic acid ( $50 \mathrm{~mm})$, and dithiothreitol (1 $\mathrm{mm}$ ), snap-frozen in liquid nitrogen, and was stored at $-80^{\circ} \mathrm{C}$ after the sample identity was coded. All analytical procedures were done with coded samples. The frozen tissues were pulverized in a ceramic mortar earlier cooled with liquid nitrogen. The pulverized tissue was extracted by repeated vortex mixing with $4 \mathrm{ml}$ of acidified methanol $\left[0.5 \%(\mathrm{v} / \mathrm{v})\right.$ of acetic acid in methanol; precooled to $\left.-20^{\circ} \mathrm{C}\right]$ containing $3^{\prime}$-O-ethyl-(-)epicatechin ( $\left.500 \mathrm{~nm}\right)$ as a recovery standard. The mixture was stored at $-80^{\circ} \mathrm{C}$ for $12 \mathrm{~h}$ to allow for cryo-assisted protein precipitation, and it was subsequently centrifuged for $15 \mathrm{~min}$ at $16,500 \times \mathrm{g}$. The supernatant was collected, and its volume was reduced to $50 \mu \mathrm{l}$ by removing the solvents under vacuum using a Speed-Vac. To hydrolyze potentially present phase II conjugates, $50 \mu \mathrm{l}$ of sample was mixed with $50 \mu \mathrm{l}$ of sodium acetate buffer $(0.2 \mathrm{M}, \mathrm{pH} 5)$, containing $\beta$-glucuronidase from bovine liver $(100,000 \mathrm{IU} / \mathrm{ml})$, and incubated for $40 \mathrm{~min}$ at $37^{\circ} \mathrm{C}$ under argon. The reaction was stopped by adding $200 \mu \mathrm{l}$ of ice-cold, acidified methanol $[0.5 \%(\mathrm{v} / \mathrm{v})$ of acetic acid in methanol]. Samples were placed at $-80^{\circ} \mathrm{C}$ for $15 \mathrm{~min}$ and centrifuged for $15 \mathrm{~min}$ at $16,500 \times \mathrm{g}$. Supernatants from five individual brain samples of the same treatment group were collected, pooled, and subjected to two subsequent extractions with $400 \mu \mathrm{l}$ of acidified ethyl acetate $[0.5 \%(\mathrm{v} / \mathrm{v})$ of acetic acid in ethyl acetate], respectively. Solvents were subsequently removed under vacuum using a Speed-Vac, and the sample was reconstituted in $50 \mu \mathrm{l}$ of methanol, before being diluted using $150 \mu$ l of sodium acetate buffer $(0.2$ $\mathrm{M}, \mathrm{pH} 5$ ). A total volume of $50 \mu \mathrm{l}$ was analyzed by HPLC as described previously (Schroeter et al., 2006). The sample content of (-)epicatechin, 3'-O-methyl-(-)epicatechin, and 4'-O-methyl-(-)epicatechin was calculated based on peak-area ratios of analyte and internal standard and was based on standard curves established using authentic, chemically pure standards (gift from Mars Incorporated). Data were expressed as flavanol amount in nanograms per milligram of tissue (wet weight).

\section{Statistical analysis}

ANOVA with repeated measures (compound by exercise by days) or (compound by days) was used for water maze acquisition. One-way ANOVA was applied to analyze the probe trials. Post hoc tests were Bonferroni and Fisher's PSLD. One-way ANOVA and Student's $t$ test were used for histological and Q-PCR experiments with a $p$ value cutoff of 0.05 . For the microarray data, $t$ statistics were analyzed with a $p$ value cutoff of 0.005 as described above. Statistical software packages used were Statview, Graph Pad (San Diego, CA) Prism 4, and SAS 8.02.

\section{Results}

\section{$(-)$ Epicatechin consumption improves memory}

\section{(-)Epicatechin consumption and exercise experiment}

In this experiment, mice received $(-$ )epicatechin-containing pellets or control food pellets and were either sedentary (CS, $n=$ 11 ; ES, $n=12$ ) or allowed to run for $2 \mathrm{~h}$ daily (CR, $n=12$; ER, $n=11$ ), for a total of $42 \mathrm{~d}$. Running distance was monitored and did not differ between CR and ER $(p>0.05)$. Animals were trained in the Morris water maze for $8 \mathrm{~d}$ with two trials per day between days 31 and 38 of the experiment (Fig. $1 A-C$ ). Two-way ANOVA with repeated measures (food by exercise by days) revealed a nonsignificant trend toward an interaction between compound consumption and running for latency $\left(F_{(1,42)}=3.95\right.$; $p<0.053$ ) (Fig. $1 A$ ) and path length $\left(F_{(1,42)}=3.07 ; p<0.087\right)$ (Fig. $1 B$ ) but not swim speed $\left(F_{(1,42)}=0.93 ; p>0.34\right)$ (Fig. $1 C$ ).

To test retention of the task, a probe trial was performed $4 \mathrm{~h}$ after the last training trial on day 8 (Fig. $1 D$ ). A second probe trial was performed $24 \mathrm{~h}$ later (Fig. $1 E$ ). The probe trials showed that only ER mice spent significantly more time in the target quadrant than in any of the other quadrants at both $4 \mathrm{~h}\left(F_{(3,40)}=6.1 ; p<\right.$ $0.002)$ and $24 \mathrm{~h}\left(F_{(3,40)}=6.5 ; p<0.001\right)$ after the last training trial. These findings indicate that retention of the task was superior in the ER group (Fig. 1D,E).

\section{(-)Epicatechin in food in sedentary mice}

To determine whether compound administration in the absence of running could benefit learning, mice ( $n=12$ per group) received ( - )epicatechin or control food pellets for $14 \mathrm{~d}$. Thereafter, mice were fed control diet for the duration of study. Testing in the Morris water maze was started after all mice had been on control diet for 1 week. Animals were trained in the water maze with four trials per day over $8 \mathrm{~d}$. Acquisition of the task did not differ between the groups $\left(F_{(1,22)}=0.10 ; p>0.75\right)$ (Fig. $\left.2 A\right)$.

Retention of the task was assessed using multiple probe trials. Specifically, the platform was removed $4 \mathrm{~h}$ after training for a $40 \mathrm{~s}$ probe trial on days 4, 6, and 8 of training, as well as $24 \mathrm{~h}, 1$ week, and 2 weeks after the last acquisition session with mice fed control (Fig. 2 B) or (-)epicatechin (Fig. 2C) diet. On day 4 of training, only the (-)epicatechin group showed a significant prefer- 
ence for the platform quadrant $(p<$ $0.05)$. On days 6 and 8 , both groups preferred the platform zone compared with the other quadrants $(p<0.05)$. However, at $24 \mathrm{~h}$ and 1 week after the last training session, only the $(-)$ epicatechin mice performed well on the probe trial $(p<0.05)$. At 2 weeks after the last training session, neither control-fed (Fig. 2B) nor (-)epicatechin-fed (Fig. 2C) mice showed a preference for the target quadrant. Thus, (-)epicatechin mice had earlier onset and longer maintenance of good performance on the probe trials (Fig. 2C), indicating that the flavanol enhanced retention of spatial memory.

\section{$(-)$ Epicatechin in water in sedentary} mice (dose-response)

Based on the food studies, it was determined that a dose of $2.5 \mathrm{mg}$ of (-)epicatechin was sufficient to improve retention in the water maze. In a subsequent study, a dose-response analysis was performed, and a comparison between the flavanol and memantine, a compound used to enhance memory (Minkeviciene et al., 2004), was made. Specifically, 3, 15, or 30 mg of (-)epicatechin (E3, E15, and E30, respectively) or memantine $(0.6 \mathrm{mg})$ per 4 $\mathrm{ml}$ of drinking water was given for $21 \mathrm{~d}$. Analysis of liquid intake showed that mice drank similar amounts of fluid per day in the control and (-)epicatechin groups (control, $4.3 \pm 0.16 \mathrm{ml}$; E3, $4.48 \pm 0.10$ $\mathrm{ml}$; E15, $4.51 \pm 0.16 \mathrm{ml}$; E30, $4.34 \pm 0.16$ $\mathrm{ml})$ but significantly less in the memantine group $(3.48+0.16 \mathrm{ml} ; p<0.01)$ compared with the other groups.

Training in the water maze was performed between days 23 and 30 with four trials per day. There was no difference between the groups in acquisition of the task $\left(F_{(4,32)}=0.86 ; p>0.49\right)$ (Fig. 3A). However, retention was significantly enhanced by $(-)$ epicatechin. Specifically, on the probe trial on day 8 , both the E3 $\left(F_{(3,24)}=7.33 ; p<0.001\right)$ and $\operatorname{E} 15\left(F_{(3,28)}=11.87 ; p<\right.$ $0.0001)$ mice showed a significant preference for the target quadrant compared with all other quadrants $(p<0.03)$, whereas control, E30, and memantine groups did not (Fig. $3 B$ ).

\section{(-)Epicatechin crosses the blood-brain barrier}

To determine whether $(-)$ epicatechin crosses the blood-brain barrier, brains from mice ( $n=5$ per group) that consumed $(-)$ epicatechin $(0,3$, or $30 \mathrm{mg}$ per day for $13 \mathrm{~d})$ were enzyme treated to hydrolyze any potentially present $O$-glucuronidated or $\mathrm{O}$-sulfated metabolites. Samples from each group were pooled and analyzed for content of $(-)$ epicatechin and $3^{\prime}$ - or $4^{\prime}-O$ methyl-epicatechin. After an oral (-)epicatechin dose of $3 \mathrm{mg} / \mathrm{d}$, $4.3 \mathrm{ng} / \mathrm{mg}$ tissue (wet weight) of (-)epicatechin and $1.5 \mathrm{ng} / \mathrm{mg}$ tissue (wet weight) of $3^{\prime}$-O-methyl- $(-)$ epicatechin were detected in perfused brain tissue. A daily dose of $30 \mathrm{mg}$ of $(-)$ epicatechin per day resulted in (-)epicatechin and $3^{\prime}$-O-methyl- (-)epicatechin at levels of $7.3 \mathrm{ng} / \mathrm{mg}$ tissue (wet weight) and 16.0 $\mathrm{ng} / \mathrm{mg}$ tissue (wet weight), respectively. No $4^{\prime}$-O-methyl(-)epicatechin was detected. The brains of mice in the $0 \mathrm{mg}$ control group did not have measurable levels of $(-)$ epicatechin or its metabolites.

\section{Cellular effects of (-)epicatechin}

\section{(-)Epicatechin does not enhance newborn hippocampal cell survival}

To determine whether the beneficial effects of $(-)$ epicatechin on memory could be mediated by an increase in hippocampal cell genesis, mice were given injections of BrdU for the first $10 \mathrm{~d}$ of the studies. (-)Epicatechin consumption did not increase cell survival in the DG. In the experiment in which (-)epicatechin in food was combined with running, there was an effect of running on cell survival $\left(F_{(1,27)}=183.0 ; p<0.0001\right)$. However, there were fewer BrdU-positive cells in the ER group compared with the CR group $(p<0.05)$. In the $(-)$ epicatechin study in sedentary mice, 

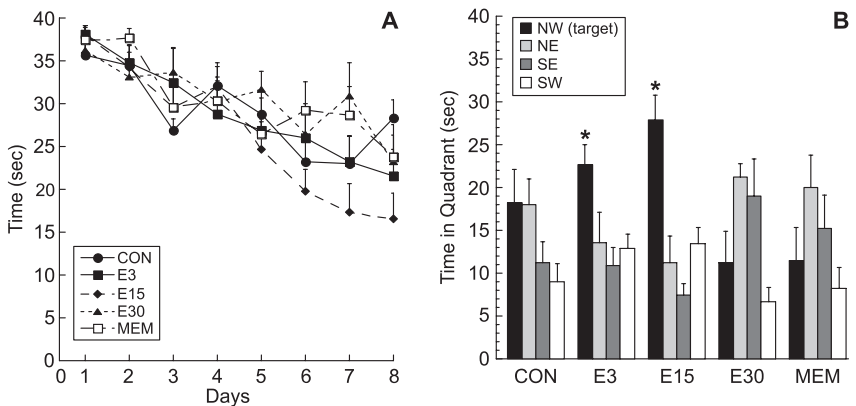

Figure 3. Dose-response of (-)epicatechin and comparison with memantine: effects on water maze learning. Mice were given (-)epicatechin $(0,3,15$, or $30 \mathrm{mg} / \mathrm{d})$ or memantine $(0.6$ $\mathrm{mg} / \mathrm{d}$ ) in drinking water for 3 weeks. $\boldsymbol{A}$, Mice were trained in the Morris water maze with four trials per day for $8 \mathrm{~d}$ between days 23 and 30 . Acquisition of the task did not differ between control (CON), $3 \mathrm{mg}$ (E3), $15 \mathrm{mg}$ (E15), and $30 \mathrm{mg}$ (E30) of (-)epicatechin or memantine (MEM). $\boldsymbol{B}$, Retention of the task was significantly improved in the E3 and E15 mice. In the $60 \mathrm{~s}$ probe trial on day 8, the $\mathrm{E} 3$ and $\mathrm{E} 15$ groups spent more time in the target area (NW) than in the other quadrants ( $p<0.03$ ), whereas $\mathrm{CON}, \mathrm{E} 30$, and MEM mice did not show a significant preference for the NW quadrant. Error bars indicate SEM. NW, Northwest; NE, northeast; SE, southeast; SW, southwest.

Table 1. (-)Epicatechin does not enhance newborn hippocampal cell survival

\begin{tabular}{lllll}
\hline & CS & CR & ES & ER \\
\hline EPI and RUN & $676(60)$ & $2731(186)^{*}$ & $678(49)$ & $2245(185)$ \\
EPI sedentary & $761(68)$ & & $741(49)$ & \\
\hline
\end{tabular}

Mice received BrdU ( $50 \mathrm{mg} / \mathrm{kg}$ ) daily for the first $10 \mathrm{~d}$ of the experiments. Survival of the total number of BrdUlabeled cells in the right DG was assessed $33 \mathrm{~d}$ after the last BrdU injection when (-)epicatechin was combined with running (EPI and RUN) mice and $39 \mathrm{~d}$ later in the study of EPI in sedentary mice. Wheel running ( $2 \mathrm{~h}$ daily) increased newborn cell survival in CR and ER. However, ER mice had significantly fewer new cells than CR animals $\left({ }^{*} p<0.05\right)$. There was no difference between the groups under sedentary conditions. Data are presented as means (SEM).

there was no difference between the groups $\left(t_{(14)}=.22 ; p>.83\right)$ (Table 1).

\section{(-)Epicatechin enhances angiogenesis}

Previous work has shown that (-)epicatechin enhances cardiovascular function in humans (Schroeter et al., 2006). To determine whether $(-)$ epicatechin affects brain vasculature, coronal sections derived from sedentary mice that received (-)epicatechin or control diet for 2 weeks and were perfused 5 weeks later were stained with tomato lectin. Blood vessel density was analyzed in the three hippocampal subfields: DG, including the molecular layer [controls, $40.20 \pm 0.60 \mathrm{~mm}^{2}$; (-)epicatechin, $39.06 \pm 0.68 \mathrm{~mm}^{2}$ ], area CA3 [controls, $2.06 \pm 0.1 \mathrm{~mm}^{2}$; (-)epicatechin, $2.28 \pm 0.1 \mathrm{~mm}^{2}$ ], and area CA1 [controls, 16.92 $\mathrm{mm}^{2}$; (-)epicatechin, $19.89 \mathrm{~mm}^{2}$ ]. The size of the areas measured did not differ between the groups for each hippocampal subfield $(p>0.05)$. Using a semiautomatic analysis (MetaMorph) to quantify lectin-stained vessels, we showed there was a significant increase in DG vasculature in flavonol-treated mice $\left.t_{(14)}=3.26 ; p<0.006\right)$. No change was found in lectin staining in area CA3 $\left(t_{(14)}=0.99 ; p>0.33\right)$, and a trend that did not reach statistical significance was observed for area CA1 $\left(t_{(14)}=2.00\right.$; $p<0.065$ ) (Table 2, Fig. 4)

Lectin staining was also enhanced in the DG of mice that received $(-)$ epicatechin diet with running for 6 weeks $\left(F_{(1,39)}=\right.$ 7.26; $p<0.01)$. Specifically, the percentage of DG area covered with blood vessels was quantified in the CS $(3.96 \pm 0.40 \%)$, CR $(3.87 \pm 0.35 \%)$, ES $(5.02 \pm 0.61 \%)$, and ER $(5.80 \pm 0.72 \%)$ groups. Together, these findings suggest that the beneficial effects of the compound on memory function in both sedentary and exercise conditions may be mediated in part by increased angiogenesis.
Table 2. (-)Epicatechin consumption increases angiogenesis

\begin{tabular}{llll}
\hline & DG (\%) & Area CA3 (\%) & Area CA1 (\%) \\
\hline CON & $3.41(0.45)$ & $5.28(0.39)$ & $6.71(0.41)$ \\
EPI & $5.62(0.51)^{*}$ & $5.91(0.41)$ & $9.14(0.38)$ \\
\hline
\end{tabular}

Mice consumed (-)epicatechin (EPI) or control (CON) diet for 2 weeks and were then given control diet for 5 more weeks. The percentage area covered by blood vessels was quantified in the DG, area CA3, and area CA1. (-)Epicatechin treatment significantly increased angiogenesis in the $D G\left({ }^{*} p<0.006\right)$ and resulted in a trend toward an increase in area CA1 $(p<0.065)$. Data are presented as means (SEM).

\section{(-)Epicatechin increases spine density}

To investigate whether the improved learning observed with ( -)epicatechin could be associated with changes in spine density in hippocampal neurons, DG granule cells were labeled with DiI. Confocal images of dendritic processes in the outer half of the molecular layer were analyzed for total protrusion and mushroom spine densities in tissue from mice ( $n=4$ per group) that received ( - )epicatechin with or without running for 6 weeks. Two-way ANOVA showed that there was a significant main effect of diet on spine density $\left(F_{(1,12)}=9.4 ; p<0.009\right)$, but not of exercise $\left(F_{(1,12)}=2.77 ; p>0.12\right)$, and no interaction between diet and exercise $\left(F_{(1,12)}=0.76 ; p>0.39\right)$. Specific comparisons showed that neurons from the ER mice had a greater spine density than neurons from CS $(p<0.014)$ or CR $(p<0.028)$ mice but not ES ( $p>0.05)$ mice (Fig. 5). Subsequently, mushroom spines (Harris and Kater, 1994) were quantified in each condition. There was no difference in mushroom spine density between the groups $\left(F_{(1,12)}=0.40 ; p>0.82\right)$.

\section{Microarray analysis}

Whole hippocampus was dissected from mice that had received ( - epicatechin or control diet daily with or without running for 6 weeks. For each condition, hippocampal tissue was dissected from three mice, and RNA was isolated and hybridized to Affymetrix mouse GeneChip arrays as independent replicates $(n=$ 3 per group). To identify genes that changed significantly, we compared the normalized signal estimates from ES to CS groups and from ER to CR groups. In Figure 6, each probe set complementary to known genes is represented by a $t$ statistic reflecting whether it was enriched (or depleted) in ES versus CS ( $y$-axis) and ER versus CR ( $x$-axis).

Next, we analyzed the probes that were enriched or depleted in ER versus CR but did not change in ES versus CS (Fig. 6A, $B$; Table 3 contains the top 10 genes upregulated and downregulated in ER vs CR). In the ER group, increased expression of genes associated with learning, such as synaptosomal-associated protein 25 (SNAP-25) (Hou et al., 2006) and kinesin family member 17 (Kif17) (Wong et al., 2002), was found. In addition, Hey1, essential for Notch1 signaling and angiogenesis, was upregulated (Fischer et al., 2004). Furthermore, in ER, decreased expression of genes associated with inflammation and cell death, such as Tnf (tumor necrosis factor), Lypla3 (lysophospholipase 3), Il20 (interleukin 20), and Casp3 (caspase-3), was observed, suggesting that the compound may attenuate neurodegenerative disease (Hirsch et al., 2003) when combined with physical activity. Moreover, Dyrk2 [dual-specificity tyrosine-(Y)-phosphorylationregulated kinase 2] expression, part of a kinase family implicated in the learning deficits of Down's syndrome, was reduced, consistent with research using green tea polyphenols in culture (Adayev et al., 2006).

Analysis of the probes that were significantly enriched in (-)epicatechin without running (Fig. 6C,D; Table 3 contains the top 10 genes enriched or depleted in ES vs CS) revealed several genes of interest. For example, Nfatcl (nuclear factor of activated 
T-cells, cytoplasmic, calcineurin dependent 1), important for neurite outgrowth (Graef et al., 2003) and angiogenesis (Zaichuk et al., 2004), was enriched. In addition, Notch1, a developmental regulator of cell fate and angiogenesis (Fischer et al., 2004) that also plays a role in memory function (Costa et al., 2005), and Cdh5 (cadherin-5), which is important for synaptic plasticity (Tang et al., 1998), are upregulated. Furthermore, decreased expression of inflammatory response regulator $\mathrm{Ccl} 21 b$ [chemokine (C-C motif) ligand 21b] and the gene encoding lipoprotein lipase $(L p l)$, which is implicated in neurodegeneration and Alzheimer's disease (Mead et al., 2002), was observed in ES mice.

Interestingly, only four genes were upregulated by $(-)$ epicatechin, with or without running (ES and ER). Just one of these genes, P2ry14, is an annotated gene, whereas the others correspond to Affymetrix probe sets 1449720_at, 1458771_at, and 1433219_at. It should be noted that $\mathrm{P} 2 \mathrm{y}$ receptors mediate nitric oxide (NO) production (Kittner et al., 2003), and so may play a role in flavanolmediated changes in cell signaling and vasculature (Fig. 6e).

To confirm the validity of the microarray analysis, Q-PCR was performed for a subset of genes. The expression patterns of anti-Mullerian hormone $(A m h)$, protein tyrosine phosphatase, nonreceptor type 11 (Ptpn11), and transmembrane protein 102 (Tmem102) were consistent with the Affymetrix GeneChip array data. Because an example of genes changed in CS versus ES, the relative amount of Ptpn 11 mRNA was significantly decreased in ES $(0.65 \pm 0.08)$ compared with CS $\left(1.00 \pm 0.06 ; t_{(8)}=3.38\right.$; $p<0.01)$. In addition, for genes that were analyzed in CR versus ER, two candidates, Amh and Tmem102, were tested. Amh was upregulated in ER $(1.37 \pm 0.22)$ compared with CR (1.09 \pm 0.19). Tmem102 expression was reduced in ER $(0.69 \pm 0.13)$ compared with CR $(0.94 \pm 0.11)$. The changes in Amh and Tmem102 expression were in the same direction as predicted by the microarray analysis but did not reach statistical significance $(p>0.05)$.

\section{Discussion}

The present study was designed to determine whether cognition, newborn cell survival, and angiogenesis could be influenced by a flavanol-rich diet. We found that memory, hippocampal vascularization, and neuronal spine density, but not new cell survival, were enhanced in mice fed a (-)epicatechin-containing diet compared with controls. Furthermore, the combination of exercise and (-)epicatechin treatment was even more beneficial for cognition. It should be noted, though, that retention in the water maze was improved regardless of variations in duration of flavanol administration or housing conditions. Moreover, microarray analysis indicated that genes associated with learning and angiogenesis were upregulated, whereas those involved with inflam-

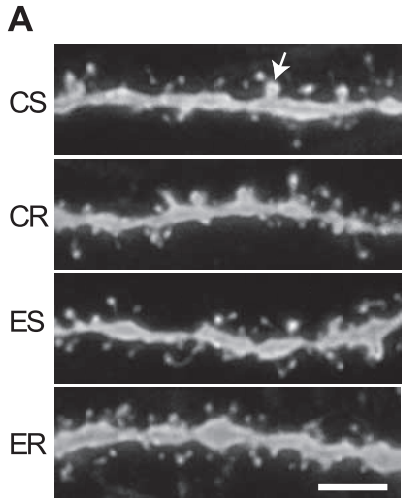

B

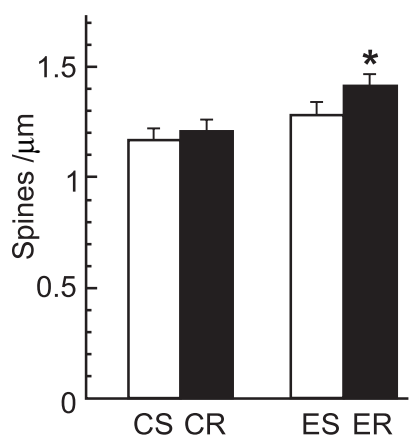

Figure 5. Dil labeling of DG granule cells in mice that received control or (-)epicatechin diet under sedentary or running conditions for 6 weeks. $\boldsymbol{A}$, Representative images of Dil-labeled dendritic fragments in the outer molecular layer of the DG in CS, CR, ES, and ER mice. The arrow indicates a mushroom spine of which the estimated surface area is no less than $0.4 \mu \mathrm{m}^{2}$. Scale bar, $5 \mu \mathrm{m}$. $\boldsymbol{B}$, Spine-density quantification showed that neurons from ER mice had more spines than cells from $C S\left({ }^{*} p<0.014\right)$ or $C R\left({ }^{*} p<0.03\right)$ animals. Error bars indicate SEM.

mation and cell death were decreased by (-)epicatechin consumption.

In initial studies to determine whether (-)epicatechin ingestion can improve learning, we combined flavanol consumption with a limited amount of exercise for 6 weeks. Mice were trained in the Morris water maze, a well established assay for spatial 


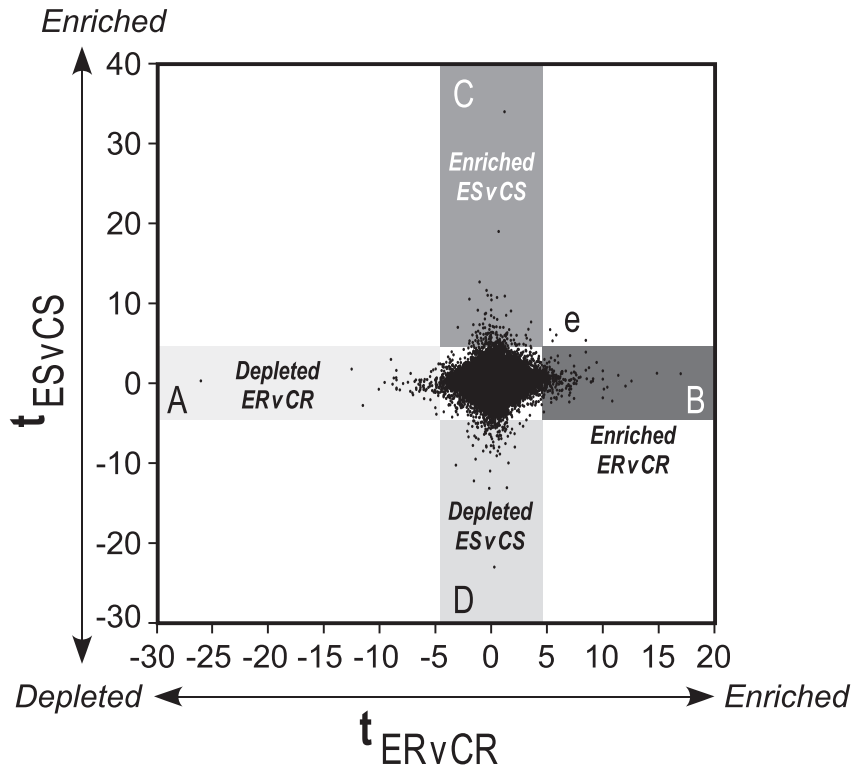

Figure 6. Two-dimensional representation of gene expression changes resulting from 6 weeks of daily (-)epicatechin consumption with or without running. $t$ statistics and cutoffs $(p<0.005)$ for ER versus (R (ERvCR; $x$-axis) and ES versus CS (ESvCS; $y$-axis) mice were computed as described in Materials and Methods. Each $(x, y)$ point in the graph represents the $t$ statistic $\left(t_{\mathrm{ER}, \mathrm{CR}}, t_{\mathrm{ES}, \mathrm{CS}}\right)$ for a probe set. $\boldsymbol{A}-\boldsymbol{D}$, Specifically, genes that are depleted (A) or enriched $(\boldsymbol{B})$ in ER are shown in the horizontal axis; enriched $(\boldsymbol{C})$ or depleted $(\boldsymbol{D})$ gene expression with $(-$ )epicatechin alone (ES) is represented in the vertical axis. $\boldsymbol{e}$, Four genes that are uniquely enriched in both sedentary and running flavanol-treated mice.

learning (Morris et al., 1982), with two trials per day (van Praag et al., 1999). In this paradigm, $2 \mathrm{~h}$ of daily exercise alone or ( - )epicatechin only did not improve performance in the water maze. The combination of (-)epicatechin and exercise, however, enhanced retention of the task. Specifically, the ER mice showed superior performance on the probe trials at 4 and $24 \mathrm{~h}$ after the last training session. These findings are consistent with research in dogs showing that environmental enrichment combined with a diet containing phytochemicals and vitamin $\mathrm{E}$ had a greater effect on cognition than either condition alone (Milgram et al., 2005).

Neither running nor long-term administration of the flavanol compound is essential for enhanced retention. When sedentary mice received $(-)$ epicatechin for 2 weeks and then were trained in the water maze with four trials per day for $8 \mathrm{~d}$, multiple probe trials showed that learning was faster and retention was longer in $(-)$ epicatechin-treated mice. Moreover, when $(-)$ epicatechin was given in water, the flavanol improved memory at a dose comparable to the one given in food $(3 \mathrm{mg})$ and at a higher dose (15 mg) as well. The highest dose (30 mg) was not effective, suggesting that more flavanol is not always better for brain function. In this same experiment, memantine, a compound reported to enhance memory function (Barnes et al., 1996; Minkeviciene et al., 2004), did not enhance retention. The same dose of memantine $(30 \mathrm{mg} / \mathrm{kg} / \mathrm{d})$ was used as in the other studies, albeit for a shorter time period of 3 weeks, rather than 4 or 8 weeks (Barnes et al., 1996; Minkeviciene et al., 2004). In addition, the memantine-treated mice drank less, reducing the daily dose by $\sim 10 \%$. Our findings, however, are consistent with other research indicating that memantine does not improve learning (Creeley et al., 2006).

Several researchers have shown that certain flavanoid-rich foods enhance learning; however, these studies were often per- formed in aged animals or transgenic mouse models for neurodegenerative disease (Joseph et al., 1999; Hartman et al., 2006). In this context, a dietary intervention study using flavonoid-rich pomegranate juice was not effective in wild-type animals (Hartman et al., 2006). In addition, often a mixture of various flavanoids has been used in which the active ingredient remains unknown, limiting data interpretation. In a recent study, the flavanol fisetin was found to improve long-term potentiation and learning through a CREB/ERK (cAMP response element-binding protein/extracellular signal-regulated kinase) mechanism (Maher et al., 2006). Although an oral feeding paradigm was used to assess learning in vivo, the mechanistic insight is based on ex vivo treatment of tissue slices. This approach excludes factors such as absorption, metabolism, and tissue distribution, which may alter compound bioactivity. In addition, it is not clear whether this flavanol, its metabolites, or other compounds tested in a similar way can cross the blood-brain barrier. We used chemically pure (-)epicatechin, because its metabolism in mammals is well defined (Schroeter et al., 2006). Indeed, (-)epicatechin and its metabolites were detected in brain tissue of mice that were fed the compound, suggesting that ( - )epicatechin affects brain function directly. Moreover, systemic injection of a mixture of $(-)$ epicatechin metabolites [3'- and $4^{\prime}-O$-methyl- $(-)$ epicatechin $(\mathrm{w} / \mathrm{w}$ $1: 1$; Mars Incorporated)] improved learning in mice (supplemental Fig. 1, available at www.jneurosci.org as supplemental material).

Recent research in humans has shown that $(-)$ epicatechin consumption enhances peripheral circulation (Schroeter et al., 2006) and that a flavanol-rich (-)epicatechin-containing beverage can influence cortical blood flow (Fisher et al., 2006; Francis et al., 2006). However, our study provides the first direct evidence, using lectin staining, that oral administration of $(-)$ epicatechin enhanced angiogenesis in the brain and thus might improve memory. In particular, vasculature was increased in the DG of the hippocampus. Whether this enhancement reflects an increase in size of existing vessels or the genesis of new blood vessels remains to be determined. Interestingly, new cell survival in this neurogenic brain region was not improved. This finding indicates that changes in the vascular niche (Palmer et al., 2000; Pereira et al., 2007) induced by (-)epicatechin are not necessarily predictive of effects on cell genesis. It is likely that additional factors, such as changes in neurotrophin gene expression, may be important for the genesis of new cells.

In the experiment in which the flavanol diet and exercise are combined, we show that new cell survival is increased in both the exercise-only (CR) and ER groups. An apparent paradox of these results is that cell genesis is increased to a greater extent in $\mathrm{CR}$ than in ER but that memory is improved only in ER. In contrast to unlimited voluntary exercise (van Praag et al., 1999, 2005), 2 h of daily running is not sufficient to improve memory function when the mice are trained with two trials per day. This paradigm was chosen to prevent a ceiling effect of running on learning that could mask consequences of flavanol intake. It is of interest, however, that $2 \mathrm{~h}$ of daily exercise does improve retention when mice are trained with four trials rather than two trials per day in the water maze (data not shown). Furthermore, although cell genesis was not increased as much in ER as in CR, it should be noted that BrdU labeling is only an indication of cell quantity. Given our data showing that the flavanol increased spine density in existing cells, it is quite possible that the morphology of newborn cells is changed in a similar manner. The reason for the attenuated cell genesis in ER is likely that (-)epicatechin increases NO levels (Schroeter et al., 2006) in the brain, which may lead to reduced 
Table 3. Microarray analysis of hippocampal tissue of mice that consumed (-)epicatechin

\begin{tabular}{|c|c|c|c|c|}
\hline Gene & Description & $t$ statistic ESvCS & $t$ statistic ERvCR & $\begin{array}{l}\text { Affymetrix probe set } \\
\text { identifier }\end{array}$ \\
\hline \multicolumn{5}{|c|}{ A. (-)Epicatechin increases gene expression } \\
\hline Nfatc1 & Nuclear factor of activated T-cells, cytoplasmic, calcineurin-dependent 1 & 34 & 1.19 & 1425761_a_at \\
\hline Sart2 & Squamous cell carcinoma antigen recognized by T-cell 2 & 19 & 0.67 & 1455795_at \\
\hline Notch1 & Notch gene homolog 1 (Drosophila) & 11.62 & -0.42 & 1418633_at \\
\hline Ptpn6 & Protein tyrosine phosphatase, nonreceptor type 6 & 11 & -0.3 & 1460188_at \\
\hline Parvg & Parvin, $\gamma$ & 10.91 & 1.21 & 1416876_at \\
\hline Mfap2 & Microfibrillar-associated protein 2 & 10.51 & -1.95 & 1417359_at \\
\hline Zfp553 & Zinc finger protein 553 & 10.42 & 0.03 & 1426564_at \\
\hline$C d c 20$ & Cell division cycle 20 homolog (Saccharomyces cerevisiae) & 9.05 & 1.77 & 1416664_at \\
\hline Smad5 & MAD homolog 5 (Drosophila) & 8.75 & -0.47 & 1451873_a_at \\
\hline Pomt2 & Protein-0-mannosyltransferase 2 & 8.67 & -0.55 & 1433644_at \\
\hline \multicolumn{5}{|c|}{ B. $(-)$ Epicatechin decreases gene expression } \\
\hline Clca5 & Chloride channel calcium activated 5 & -23 & 0.27 & 1438109_at \\
\hline Exosc2 & Exosome component 2 & -12.25 & -1.54 & 1426630_at \\
\hline$C d 52$ & CD52 antigen & -10.25 & -3.15 & 1460218_at \\
\hline $\operatorname{Scx}$ & Scleraxis & -9.5 & -1.4 & 1456291_x_at \\
\hline $\operatorname{Tm} 4 s f 5$ & Transmembrane 4 superfamily member 5 & -8.85 & 0.77 & 1424445_at \\
\hline Sus6 & Seminal vesicle secretion 6 & -8.49 & 0.59 & 1418548_at \\
\hline Trim45 & Tripartite motif-containing 45 & -8 & 0.71 & 1441412_s_at \\
\hline$L p l$ & Lipoprotein lipase & -7.86 & 0.21 & 1415904_at \\
\hline Rp/35 & Ribosomal protein L35 & -7.82 & -0.02 & 1434231_x_at \\
\hline Hes3 & Hairy and enhancer of split 3 (Drosophila) & -7.37 & 0.19 & 1422409_at \\
\hline \multicolumn{5}{|c|}{ C. (-)Epicatechin and running increase gene expression } \\
\hline Amh & Anti-Mullerian hormone & -2.25 & 10.84 & 1450573_at \\
\hline Kif17 & Kinesin family member 17 & -0.75 & 10.09 & 1422762_at \\
\hline Snap25 & Synaptosomal-associated protein 25 & 0.55 & 9.14 & 1416828_at \\
\hline Al836003 & Expressed sequence Al836003 & 0.28 & 9.09 & 1435512_at \\
\hline Zfp535 & Zinc finger protein 535 & 0.15 & 8.95 & 1418033_s_at \\
\hline Hist1h4j & Histone cluster 1, H4c & 1.94 & 8.76 & 1431658_at \\
\hline Mapk12 & Mitogen-activated protein kinase 12 & 0.3 & 7.67 & 1449283_a_at \\
\hline Ogg1 & 8-0xoguanine DNA-glycosylase 1 & 1.27 & 7.55 & 1430078_a_at \\
\hline Ap3s2 & Adaptor-related protein complex $3, \sigma 2$ subunit & 1.43 & 7.43 & 1441993_at \\
\hline Impdh1 & Inosine $5^{\prime}$-phosphate dehydrogenase 1 & -0.05 & 7.41 & 1423239_at \\
\hline Hey1 & Hairy enhancer of split with YRPW motif & -0.72 & 7.16 & 1419303_at \\
\hline \multicolumn{5}{|c|}{ D. (-)Epicatechin and running decrease gene expression } \\
\hline Dyrk2 & Dual-specificity tyrosine-(Y)-phosphorylation regulated kinase 2 & 1.78 & -12.5 & 1456502_at \\
\hline Tnf & Tumor necrosis factor & -0.77 & -10.06 & 1419607_at \\
\hline Tmem102 & Transmembrane protein 102 & 2.99 & -8.97 & 1453318_at \\
\hline Rpusd1 & RNA pseudouridylate synthase domain containing 1 & -0.11 & -8.83 & 1453253_a_at \\
\hline Nup43 & Nucleoporin 43 & 0.65 & -8.72 & 1432188_s_at \\
\hline Lypla3 & Lysophospholipase 3 & 0.41 & -8.49 & 1422341_s_at \\
\hline St3gal1 & ST3 $\beta$-galactoside $\alpha$-2,3-sialyltransferase 1 & 1.58 & -8.49 & 1418946_at \\
\hline Cyb5r2 & Cytochrome b5 reductase 2 & -0.83 & -8.18 & 1459448_at \\
\hline Pitpnm 1 & Phosphatidylinositol membrane-associated 1 & -0.06 & -7.9 & 1425760_a_at \\
\hline Elov/3 & Elongation of very long chain fatty acids & 0.12 & -7.46 & 1420722_at \\
\hline
\end{tabular}

Microarray analysis of hippocampal tissue in mice fed (-)epicatechin daily for 6 weeks with or without physical activity. The 10 annotated genes with highest $t$ statistics that are either upregulated (A, C) or downregulated (B, D) by $(-)$ epicatechin in sedentary $(A, B)$ or running $(C, D)$ mice are listed. ESvCS, ES versus CS; ERvCR, ER versus CR.

cell genesis (Packer et al., 2003). Indeed, genes that suppress cell proliferation [Ptpn11; maximum binding protein (MNT); B-cell translocation gene 1, antiproliferative (Btg1); AXIN2 (axin2)] were upregulated with $(-)$ epicatechin treatment. Additional studies investigating the effects of $(-)$ epicatechin on cell division are needed to address these possible mechanisms of flavanol action.

In addition to cerebral blood flow, neuronal spine density is considered important for learning and memory (Harris and Kater, 1994). (-)Epicatechin, combined with exercise, increased neuronal spine density in the DG. These findings confirm and extend previous work showing that $(-)$ epicatechin influences neurite outgrowth in vitro (Reznichenko et al., 2005). In addition, microarray analysis showed that (-)epicatechin consumption increased expression of several genes associated with neurite ex- tension and synaptic plasticity, such as SNAP-25, Kif17, and Mapk. The changes appear to be quite stable, because both the histological and gene expression effects were observed after 6 weeks of daily flavanol consumption. Together, these findings indicate that (-)epicatechin causes long-lasting structural and functional changes in the mouse brain, especially when linked with physical activity.

It appears that the hippocampus is particularly responsive to the effects of flavanols. Microarray analysis of gene expression in hippocampal tissue after 6 weeks of daily flavanol consumption showed that (-)epicatechin treatment alone, without running, resulted in an upregulation (and downregulation) of genes that did not change when $(-)$ epicatechin was combined with running. Instead, a different set of genes was altered with flavanol consumption and exercise. However, in both conditions [i.e., 
$(-)$ epicatechin only and (-)epicatechin with physical activity], the expression of genes associated with learning, synaptic plasticity, and angiogenesis was increased, whereas genes relevant to learning deficits and neurodegeneration were decreased. Furthermore, similar to other phytochemical dietary supplements (Baur et al., 2006) and consistent with peripheral effects of flavanols (Mao et al., 2002), (-)epicatechin lowered the expression of gene products that mediate inflammation, lipid synthesis, and cell death.

In conclusion, consumption of (-)epicatechin increases memory function, hippocampal angiogenesis, and neuronal spine density. The effects of the flavanol on spatial memory are enhanced by physical activity. Thus, an active lifestyle combined with a flavanol-rich diet may prevent aging-related cognitive disorders and/or neurodegenerative disease.

\section{References}

Abd El Mohsen MM, Kuhnle G, Rechner AR, Schroeter H, Rose S, Jenner P, Rice-Evans CA (2002) Uptake and metabolism of epicatechin and its access to the brain after oral ingestion. Free Radical Biol Med 33:1693-1702.

Adayev T, Chen-Hwang MC, Murakami N, Wegiel J, Hwang YW (2006) Kinetic properties of a MNB/DYRK1A mutant suitable for the elucidation of biochemical pathways. Biochemistry 45:12011-12019.

Adlard PA, Perreau VM, Pop V, Cotman CW (2005) Voluntary exercise decreases amyloid load in a transgenic model of Alzheimer's disease. J Neurosci 25:4217-4221.

Aimone JB, Wiles J, Gage FH (2006) Potential role for adult neurogenesis in the encoding of time in new memories. Nat Neurosci 9:723-727.

Barnes CA, Danysz W, Parsons CG (1996) Effects of the uncompetitive NMDA receptor antagonist memantine on hippocampal long-term potentiation, short-term exploratory modulation and spatial memory in awake, freely moving rats. Eur J Neurosci 8:565-571.

Baur JA, Pearson KJ, Price NL, Jamieson HA, Lerin C, Kalra A, Prabhu VV, Allard JS, Lopez-Lluch G, Lewis K, Pistell PJ, Poosala S, Becker KG, Boss O, Gwinn D, Wang M, Ramaswamy S, Fishbein KW, Spencer RG, Lakatta EG, et al. (2006) Resveratrol improves health and survival of mice on a high-calorie diet. Nature 444:337-342.

Butterfield D, Castegna A, Pocernich C, Drake J, Scapagnini G, Calabrese V (2002) Nutritional approaches to combat oxidative stress in Alzheimer's disease. J Nutr Biochem 13:444-461.

Costa RM, Drew C, Silva AJ (2005) Notch to remember. Trends Neurosci 28:429-435.

Creeley C, Wozniak DF, Labruyere J, Taylor GT, Olney JW (2006) Low doses of memantine disrupt memory in adult rats. J Neurosci 26:3923-3932.

Fischer A, Schumacher N, Maier M, Sendtner M, Gessler M (2004) The Notch target genes Heyl and Hey2 are required for embryonic vascular development. Genes Dev 18:901-911.

Fisher ND, Sorond FA, Hollenberg NK (2006) Cocoa flavanols and brain perfusion. J Cardiovasc Pharmacol 47:S210-S214.

Francis ST, Head K, Morris PG, Macdonald IA (2006) The effect of flavanolrich cocoa on the fMRI response to a cognitive task in healthy young people. J Cardiovasc Pharmacol 47:S215-S220.

Friedland RP, Fritsch T, Smyth KA, Koss E, Lerner AJ, Chen CH, Petot GJ, Debanne SM (2001) Patients with Alzheimer's disease have reduced activities in midlife compared with healthy control-group members. Proc Natl Acad Sci USA 98:3440-3445.

Gage FH (2000) Mammalian neural stem cells. Science 287:1433-1438.

Graef IA, Wang F, Charron F, Chen L, Neilson J, Tessier-Lavigne M, Crabtree GR (2003) Neurotrophins and netrins require calcineurin/NFAT signaling to stimulate outgrowth of embryonic axons. Cell 113:657-670.

Griesbach GS, Hovda DA, Molteni R, Wu A, Gomez-Pinilla FJ (2004) Voluntary exercise following traumatic brain injury: brain-derived neurotrophic factor upregulation and recovery of function. Neuroscience 125:129-139.

Harris KM, Kater SB (1994) Dendritic spines: cellular specializations imparting stability and flexibility to synaptic function. Annu Rev Neurosci 17:341-371.

Hartman RE, Shah A, Fagan AM, Schwetye KE, Parsadanian M, Schulman
RN, Finn MB, Holtzman DM (2006) Pomegranate juice decreases amyloid load and improves behavior in a mouse model of Alzheimer's disease. Neurobiol Dis 24:506-515.

Haque AM, Hashimoto M, Katakura M, Tanabe Y, Hara Y, Shido O (2006) Long-term administration of green tea catechins improves spatial cognition learning ability in rats. J Nutr 136:1043-1047.

Heiss C, Kleinbongard P, Dejam A, Perre S, Schroeter H, Sies H, Kelm M (2005) Acute consumption of flavanol-rich cocoa and the reversal of endothelial dysfunction in smokers. J Am Coll Cardiol 46:1276-1283.

Hirsch EC, Breidert T, Rousselet E, Hunot S, Hartmann A, Michel PP (2003) The role of glial reaction and inflammation in Parkinson's disease. Ann NY Acad Sci 991:214-218.

Hou QL, Gao X, Lu Q, Zhang XH, Tu YY, Jin ML, Zhao GP, Yu L, Jing NH, Li BM (2006) SNAP-25 in hippocampal CA3 region is required for longterm memory formation. Biochem Biophys Res Commun 347:955-962.

Hyun D, Emerson SS, Jo D, Mattson MP, de Cabo R (2006) Calorie restriction up-regulates the plasma membrane redox system in brain cells and suppresses oxidative stress during aging. Proc Natl Acad Sci USA 103:19908-19912.

Jin K, Zhu K, Sun Y, Mao XO, Xie L, Greenberg DA (2002) Vascular endothelial growth factor (VEGF) stimulates neurogenesis in vitro and in vivo. Proc Natl Acad Sci USA 99:11946-11950.

Joseph JA, Shukitt-Hale B, Denisova NA, Bielinski D, Martin A, McEwen JJ, Bickford PC (1999) Reversals of age-related declines in neuronal signal transduction, cognitive, and motor behavioral deficits with blueberry, spinach, or strawberry dietary supplementation. J Neurosci 19:8114-8121.

Kittner H, Franke H, Fischer W, Schultheis N, Krugel U, Illes P (2003) Stimulation of P2Y1 receptors causes anxiolytic-like effects in the rat elevated plus-maze: implications for the involvement of P2Y1 receptor-mediated nitric oxide production. Neuropsychopharmacology 28:435-444.

Koh SH, Kim SH, Kwon H, Kim JG, Kim JH, Yang KH, Kim J, Kim SU, Yu HJ, Do BR, Kim KS, Jung HK (2004) Phosphatidylinositol-3 kinase/Akt and GSK-3 mediated cytoprotective effect of epigallocatechin gallate on oxidative stress-injured neuronal-differentiated N18D3 cells. Neurotoxicology 25:793-802.

Kramer AF, Hahn S, Cohen NJ, Banich MT, McAuley E, Harrison CR, Chason J, Vakil E, Bardell L, Boileau RA, Colcombe A (1999) Ageing, fitness and neurocognitive function. Nature 400:418-419.

Lee J, Seroogy KB, Mattson MP (2002) Dietary restriction enhances neurotrophin expression and neurogenesis in the hippocampus of adult mice. J Neurochem 80:539-547.

Maher P, Akaishi T, Abe K (2006) Flavonoid fisetin promotes ERKdependent long-term potentiation and enhances memory. Proc Natl Acad Sci USA 103:16568-16573.

Mao TK, van de Water J, Keen CL, Schmitz HH, Gershwin ME (2002) Modulation of TNF-alpha secretion in peripheral blood mononuclear cells by cocoa flavanols and procyanidins. Dev Immunol 9:135-141.

Mattson MP (2000) Existing data suggest that Alzheimer's disease is preventable. Ann NY Acad Sci 924:153-159.

Mead JR, Irvine SA, Ramji DP (2002) Lipoprotein lipase: structure, function, regulation, and role in disease. J Mol Med 80:753-769.

Milgram NW, Head E, Zicker SC, Ikeda-Douglas CJ, Murphey H, Muggenburg B, Siwak C, Tapp D, Cotman CW (2005) Learning ability in aged beagle dogs is preserved by behavioral enrichment and dietary fortification: a two year longitudinal study. Neurobiol Aging 26:77-90.

Minkeviciene R, Banerjee P, Tanila H (2004) Memantine improves spatial learning in a transgenic mouse model of Alzheimer's disease. J Pharmacol Exp Ther 311:677-682.

Morris RGM, Garrud P, Rawlins JN, O'Keefe J (1982) Place navigation impaired in rats with hippocampal lesions. Nature 297:681-683.

Packer MA, Stasiv Y, Benraiss A, Chmielnicki E, Grinberg A, Westphal H, Goldman SA, Enikolopov G (2003) Nitric oxide negatively regulates mammalian adult neurogenesis. Proc Natl Acad Sci USA 100:9566-9571.

Palmer TD, Willhoite AR, Gage FH (2000) Vascular niche for adult hippocampal neurogenesis. J Comp Neurol 425:479-494.

Patel NV, Gordon MN, Connor KE, Good RA, Engelman RW, Mason J, Morgan DG, Morgan TE, Finch CE (2005) Caloric restriction attenuates Abeta-deposition in Alzheimer transgenic models. Neurobiol Aging 26:995-1000.

Pereira AC, Huddleston DE, Brickman AM, Sosunov AA, Hen R, McKhann 
GM, Sloan R, Gage FH, Brown TR, Small SA (2007) An in vivo correlate of exercise-induced neurogenesis in the adult dentate gyrus. Proc Natl Acad Sci USA 104:5638-5643.

Powell KE, Blair SN (1994) The public health burdens of sedentary living habits: theoretical but realistic estimates. Med Sci Sports Exerc 26:851-856.

Reznichenko L, Amit T, Youdim MB, Mandel S (2005) Green tea polyphenol (-)-epigallocatechin-3-gallate induces neurorescue of long-term serum-deprived PC12 cells and promotes neurite outgrowth. J Neurochem 93:1157-1167.

Rozen S, Skaletsky HJ (2000) Primer3 on the WWW for general users and for biologist programmers. Methods Mol Biol 132:365-386.

Scalbert A, Williamson G (2000) Dietary intake and bioavailability of polyphenols. J Nutr 130:2073S-2085S.

Schroeter H, Spencer JP, Rice-Evans C, Williams RJ (2001) Flavonoids protect neurons from oxidized low-density-lipoprotein-induced apoptosis involving c-Jun N-terminal kinase (JNK), c-Jun and caspase-3. Biochem J 358:547-557

Schroeter H, Heiss C, Balzer J, Kleinbongard P, Keen CL, Hollenberg NK, Sies H, Kwik-Uribe C, Schmitz HH, Kelm M (2006) (-)Epicatechin mediates beneficial effects of flavanol-rich cocoa on vascular function in humans. Proc Natl Acad Sci USA 103:1024-1029.

Steinmetz KA, Potter JD (1996) Vegetables, fruit, and cancer prevention: a review. J Am Diet Assoc 96:1027-1039.

Tang L, Hung CP, Schuman EM (1998) A role for the cadherin family of cell adhesion molecules in hippocampal long-term potentiation. Neuron 20:1165-1175.

Tillerson JL, Caudle WM, Reveron ME, Miller GW (2003) Exercise induces behavioral recovery and attenuates neurochemical deficits in rodent models of Parkinson's disease. Neuroscience 119:899-911.

van Praag H, Christie BR, Sejnowski TJ, Gage FH (1999) Running enhances neurogenesis, learning and long-term potentiation in mice. Proc Nat Acad Sci USA 96:13427-13431.

van Praag H, Shubert T, Zhao C, Gage FH (2005) Exercise enhances learning and hippocampal neurogenesis in aged mice. J Neurosci 25:8680-8685.

Winter B, Breitenstein C, Mooren FC, Voelker K, Fobker M, Lechtermann A, Krueger K, Fromme A, Korsukewitz C, Floel A, Knecht S (2007) High impact running improves learning. Neurobiol Learn Mem 87:597-609.

Wong RW, Setou M, Teng J, Takei Y, Hirokawa N (2002) Overexpression of motor protein KIF17 enhances spatial and working memory in transgenic mice. Proc Natl Acad Sci USA 99:14500-14505.

Yeo GW, Van Nostrand E, Holste D, Poggio T, Burge CB (2005) Identification and analysis of alternative splicing events conserved in human and mouse. Proc Natl Acad Sci USA 102:2850-2855.

Zaichuk TA, Shroff EH, Emmanuel R, Filleur S, Nelius T, Volpert OV (2004) Nuclear factor of activated $\mathrm{T}$ cells balances angiogenesis activation and inhibition. J Exp Med 199:1513-1522.

Zhao C, Teng EM, Summers Jr RG, Ming GL, Gage FH (2006) Distinct morphological stages of the dentate granule neuron maturation in the adult mouse hippocampus. J Neurosci 26:3-11. 